\title{
"Ô bicharada, toma cuidado: o Bolsonaro vai matar viado!" Cantos homofóbicos de torcidas de futebol como dispositivos discursivos das masculinidades
}

\section{Carlos Magno Camargos Mendonça'}

https://orcid.org/0000-0002-4883-3410

\author{
https://orcid.org/0000-0002-8051-126X \\ I - Universidade Federal de Minas Gerais \\ Belo Horizonte (MG), Brasil \\ II - Universidade Federal de Ouro Preto \\ Mariana (MG), Brasil
}

Felipe Viero Kolinski Machado Mendonça"

\begin{abstract}
Resumo: Sugere-se, neste artigo, que os cantos homofóbicos entoados pelas torcidas de futebol operam como dispositivos discursivos das masculinidades. No escopo de nossas reflexões, compreendemos tais discursos como corresponsáveis por propagandear/propagar discursos de ódio contra a população gay, como partícipes de uma rede discursiva que envolve outras modalidades de práticas homofóbicas (tais como os assassinatos) e, ainda, como dispositivos pedagógicos que, nos estádios e também para além deles, ensinam sobre os modos possíveis/interditados de ser homem.
\end{abstract}

Palavras-chave: cantos homofóbicos; torcidas de futebol; dispositivos discursivos das masculinidades. 


\begin{abstract}
Hey fag, be careful: Bolsonaro will kill the queers!" Homophobic songs from soccer fans as discursive dispositive of masculinities - It is suggested in this text that the homophobic chants sung by the soccer fans operate as discursive devices of masculinities. In the scope of our reflections, we understand such discourses as co-responsible for propagating and advertising hate speech against the gay population, as participants in a discursive network that involves other modalities of homophobic practices (such as murders) as well as pedagogical dispositives that, in stadiums and beyond, teach about the possible/restricted ways of being a man.
\end{abstract}

Keywords: homophobic songs; soccer fans; discursive dispositive of masculinities.

\title{
Introdução
}

No dia 16 de setembro de 2018, o Estádio Governador Magalhães Pinto, o Mineirão, sediou um jogo entre o Clube Atlético Mineiro e o Cruzeiro Esporte Clube. A rivalidade entre os dois times é lendária. Os apelidos ofensivos destinados a cada torcida idem. Nessa partida, entretanto, um entre os cânticos entoados pelos atleticanos convém ser retomado. Faltando menos de um mês para o primeiro turno das eleições que, em um segundo pleito, alçariam Bolsonaro ao posto de presidente, ouviu-se: "Ô Cruzeirense, toma cuidado: o Bolsonaro vai matar viado!". A diretoria do clube, através de vídeo e texto publicados em redes sociais ${ }^{1}$, posicionou-se de modo a combater a homofobia, lembrando que o time é plural, diverso e inclusivo.

Ainda em setembro de 2018, mas no dia 30, Luis Othavio Nunes, homossexual, gravou um vídeo na estação de metrô Sé, em São Paulo, registrando torcedores da Sociedade Esportiva Palmeiras entoando o canto: "Ô bicharada, toma cuidado: O Bolsonaro vai matar viado!". Disponibilizado em redes sociais, o material audiovisual foi veiculado por diferentes portais de notícias. Conforme destacou Luis², o canto teria começado no encontro dos torcedores com um grupo de manifestantes, pró-Bolsonaro, que se dirigia à Avenida Paulista para um ato da campanha eleitoral.

Mas a homofobia, tão enraizada no ambiente das torcidas de futebol (BANDEIRA, 2010; ALMEIDA \& SOARES, 2012; BANDEIRA \& SEFFNER, 2013), também bate à nossa porta. Em Belo Horizonte, moramos no Bairro Sagrada 
Família, região leste da capital. Somos vizinhos do Estádio Raimundo Sampaio, o Arena Independência. Em 02 de junho de 2017, por ocasião de uma partida entre Atlético e Cruzeiro, cartazes foram afixados ao longo da rua, percurso então designado para uma das torcidas. Na arte gráfica, aplicado sobre uma bandeira do arco-íris, em óbvia alusão às cores do movimento LGBT, havia o seguinte texto: "Sejam Bem-vindas". No canto superior direito, havia a constelação do Cruzeiro do Sul, em referência ao símbolo cruzeirense ${ }^{3}$. Passados mais de dois anos do episódio, restos dos cartazes, ainda legíveis, colorem a região, lembrando cotidianamente que ser gay é uma ofensa e que, dentre tantas outras consequências, físicas e simbólicas, há que se conviver, também, com a injúria (ERIBON, 2008).

Enquanto começávamos a redigir estas linhas ${ }^{4}$, ecoavam os gritos de outra partida. Era sábado, véspera de Páscoa, 20 de abril de 2019, e, mais uma vez, o Arena Independência recebia uma partida entre o Atlético e o Cruzeiro. Dessa vez, de casa, não se discernia qual equipe estava sendo ofendida, mas compreendia-se nitidamente o refrão: “Chupa rola e dá o cu, chupa rola e dá o cu, vai tomar no cu!". Mais uma vez, como agressão aos adversários, recorreu-se à homofobia e, mais especificamente, ao ato do sexo oral (chupar a rola) e à penetração anal (dá o cu, vai tomar no cu), que (também) fazem parte das práticas sexuais homossexuais.

No dia 13 de junho de 2019, o Supremo Tribunal Federal (STF) enquadrou a homofobia e a transfobia como tipo penal definido na Lei do Racismo (Lei 7.716/1989). Os ministros do STF entenderam que houve omissão do Congresso Nacional por não editar lei criminalizando tal violência. A criminalização da homofobia acendeu a chama do debate sobre as práticas homofóbicas e transfóbicas em vários espaços sociais. Não foi diferente para os estádios de futebol e as torcidas organizadas. Desde sempre, o futebol foi considerado "coisa para macho" e as manifestações homofóbicas das torcidas são uma constante em sua história. Estas manifestações, em sua maioria, são expressões verbais que desclassificam e hierarquizam os chamados homens por sobre os não homens, utilizando como argumento as formas de prazer e de existências ditas dissonantes. Em uma sociedade orientada pelas e para as práticas heterossexuais, as pessoas que escapam 
a esta perspectiva são consideradas anormais e dignas de todo o tipo de injúria (ERIBON, 2008). A decisão do STF acabou por pressionar o Supremo Tribunal de Justiça Desportiva (STJD) a posicionar-se sobre o tema. Em 19 de agosto de 2019, o STJD emitiu a Recomendação Nº1/20195, como uma ação preventiva a atos discriminatórios durante as partidas de futebol. No documento, o STJD recomenda a todos os árbitros, auxiliares e delegados das partidas que reportem nos documentos oficiais atos preconceituosos e injúrias decorrentes da orientação sexual de qualquer participante ou atleta. A Recomendação estimula os clubes a realizarem campanhas educativas para seus diversos públicos. É curioso notar que no texto da Recomendação foi usado o termo "opção sexual" e não "orientação sexual", ainda que, cabe lembrar, ninguém opte por uma sexualidade. A sexualidade é composta por um conjunto de variáveis psicológicas desenvolvidas ao longo da vida (BUTLER, 2012).

No dia primeiro de setembro de 2019, a medida do STJD não impediu que a torcida do Cruzeiro Esporte Clube entoasse um canto homofóbico no Mineirão. Desrespeitando a Recomendação, o árbitro substituto Marcelo Aparecido não registrou o fato na súmula da partida ${ }^{6}$. Ouvido por um site de notícias da capital mineira7, o presidente da Torcida Organizada Galoucura, Josimar Júnior de Souza Barros, comentou que a proibição dos cantos homofóbicos "está acabando com o espetáculo do futebol". Para Barros: "Agora estão querendo acabar com algo que, querendo ou não, já faz parte do clássico. Isso não ofende ninguém. A gente não está falando especificamente com o torcedor. Isso só está acabando com o futebol, cada vez mais. Está começando o futebol moderno, e nós não apoiamos"

\section{Propaganda e discurso de ódio: o canto homofóbico como problema de pesquisa}

A construção do que chamaríamos um problema de pesquisa inspira-se em duas estratégias propostas por Kathleen Stewart. Na primeira delas, Stewart (1996) nos convoca a pensar as vidas existentes às margens das grandes narrativas. Em um diálogo intenso com a etnografia, a autora incita a uma

\footnotetext{
5 Disponível em: <https://www.stjd.org.br/noticias/stjd-emite-recomendacao-contra-homofobia>. Acesso em: Dez. 2019.

6 Disponível em: <https://bhaz.com.br/2019/09/01/torcida-cruzeiro-canto-homofobico/>. Acesso em: Dez. 2019.

7 Disponível em: <https://bhaz.com.br/2019/09/02/galoucura-nao-banira-cantos-homofobicos/>. Acesso em: Dez. 19.
} 
outra escrita, forjada na experiência vivida, uma descrição dos momentos que afetaram a quem pesquisa. Os afetos são para ela potências capazes de alterar os movimentos dos corpos (SPINOZA, 2007; STEWART, 2007). Na segunda estratégia, Stewart (2007) apresenta uma série de curtas descrições de afetos que coloca o leitor diante de intensidades, estranhezas e incômodos com o propósito de movê-lo de seus lugares seguros de compreensão. A antropóloga não pretende uma análise social fechada e definitiva. Sua escrita oferece outras tessituras ao acontecimento, um encontro com os corpos, as vivências, os rostos.

Primeiro, as experiências relatadas nos afetaram pela convencionalidade já apontada: a homofobia nas torcidas de futebol. Posteriormente, surgiu outro incômodo: em que medida podemos entender os cânticos homofóbicos das torcidas de futebol como propaganda para uma suposta masculinidade hegemônica (CONNELL, 2003)? Em conversas informais, alguns amigos nos disseram que os cantos com ofensas a outra torcida não eram manifestações de homofobia, eram simplesmente "coisas do futebol". Esse tipo de comentário desconsidera que para todo enunciado há um enunciador, uma intencionalidade, um mundo ao qual o enunciado se refere - o mundo do texto. Sobre as marcas de enunciação no texto, ressalta Ugo Volli:

são significativas para a análise sob muitos aspectos: elas são indícios dos modos de manifestar-se do sujeito e do modo pelo qual ele assume seu enunciado, dos modos de instalar no texto o enunciador o enunciatário e suas relações, as quais propõe hipóteses de autor e leitor, e transformações progressivas do ponto de vista, produzem alguns efeitos de sentidos particulares, como os efeitos de realidade, e em geral tudo aquilo que torna eficaz a comunicação. (VOLLI, 2007, p. 136)

Nessa perspectiva, ninguém seria responsável pelo conteúdo daqueles textos verbais ou visuais disparados pelas torcidas. Naturalizar a ofensa por orientação sexual ou identidade de gênero seria como desconsiderar os efeitos de dada prática no contexto enunciativo de um país com altos índices de crimes homofóbicos. Os dados do relatório anual Grupo Gay da Bahia apontam 420 mortes de gays, lésbicas, bissexuais, travestis e transexuais no país em 2018. O número, ainda que inferior ao de 2017 (quando foram 445 vítimas), segue sendo alarmante ${ }^{8}$. Diante de uma suposta resposta positiva para a primeira 
pergunta, uma intriga se fazia mais forte: de que maneira aqueles cânticos participam da textualidade dos crimes de ódio e em que medida eles podem ser tomados como propaganda desta prática criminosa?

O senso comum entende a propaganda como uma forma de divulgação de mensagens por meio de anúncios, veiculados sobre diversos tipos de suporte midiático. Entretanto, gostaríamos de lembrar outras acepções do termo, em especial aquela que se refere à propaganda como critério para tornar público um valor. Assim, a propaganda é a propagação de ideias e valores, bem como uma construtora de argumentos. Por conseguinte, poderíamos compreender que quem faz uma propaganda procura a divulgação de suas palavras e atos. Uma propaganda será sempre uma vontade de ação.

Seguindo pelo caminho da vontade de ação, a perspectiva de Jacques Ellul (2014) recupera os trabalhos de Harold Lasswell para dizer da utilidade fim da propaganda: maximização do poder e, consequentemente, subordinação de grupos e de indivíduos com o mínimo dispêndio para o poder. Publicado originalmente em 1938, diante da emergência de totalitarismos, a obra de Lasswell "Propaganda technique in the world war" elenca quatro fins prioritários para a propaganda: contar histórias de atrocidades com o objetivo de mobilizar o ódio contra o inimigo; fomentar a amizade entre os aliados; buscar laços e colaborações por parte de quem está neutro; desmoralizar o inimigo. Lasswell (2013) interessava-se pelo estudos dos conteúdos da propaganda em comunicações massivas e seus efeitos sobre o público a quem se destinava a mensagem. Diante dos confrontos mundiais, Lasswell (2013) considerou a propaganda como uma máquina de guerra, como parte integrante do conflito. Sobre isso, afirma Ellul (2014, p. 7): “Antes da guerra, a propaganda é um substituto das violências físicas; durante a guerra, seu suplemento." Sob o ponto de vista de Lasswell (2013), uma análise de conteúdo da propaganda deve levar em conta o número de vezes que um símbolo aparece em uma mensagem; a direção da persuasão simbólica; a intensidade dos símbolos e seus impactos sobre a opinião pública. Ainda que nossas inspirações metodológicas passem por diversos campos, interessa-nos buscar, no pensamento de Lasswell (2013), o princípio de que quanto mais estratégico for um ato de propaganda mais efetivo será o esforço de guerra.

Remontando para nossa questão sobre os referidos cânticos na tessitura de ódio, passamos a entender que entoar os cânticos é parte de um rito 
comunicacional que combina vigilância e controle. Por rito compreendemos os atos cerimoniais onde são comunicados, por uma sucessão de palavras repetidas, valores e regras. Os ritos mantêm ou atualizam um mito (TURNER, 2008). No trabalho de Victor Turner há uma convicção no caráter dinâmico das relações sociais. Estas interações ativas e suas consequências refletiram uma forma no processo do tempo social (TURNER, 2008). O antropólogo criou uma metáfora estética para esta forma: o drama social. A metáfora estética de Turner tem especial atenção para a perspectiva inter-relacional da performance. A performance estaria encarregada do trânsito entre atividades culturais em diferentes condições. Aparece aqui uma grande contribuição da noção de drama social: a performance como borda, como lugar de negociação, como margem (CARLSON, 2010). Mas a performance é também lugar de tensões e de disputas. Ela possibilita o rompimento com a tradição ou reafirma a mesma. As estruturas tradicionais são reticulares, se consolidam, não sem conflitos, performativamente. Os conflitos são parte da dinâmica social. O estabelecimento das condutas não é algo pacífico na experiência social. No conflito, uma tríade: a comunicação, as performatividades textuais e simbólicas, as performances corporais. Ao estudar o interesse de Turner pelo ritual e pelos símbolos rituais, comenta Maria Laura Viveiros de Castro Cavalcanti:

\footnotetext{
Esse conceito - centrado na ideia dos símbolos como propulsores da ação social e pessoal na arena pública, e baseado nas propriedades simbólicas de multivocalidade, complexidade associativa e abertura para diversos campos semânticos, ambiguidade, polaridade sensorial e ideológica - está na base da proposta turneriana de uma simbologia processual e comparativa (TURNER, 1975, p. 155): uma abordagem focada nos 'símbolos individuais, em seus campos semânticos e destino processual na medida em que se movimentam através do cenário de uma performance ritual específica e reaparecem em outros tipos de ritual, ou mesmo se transferem de um gênero para o outro, por exemplo, do ritual para um ciclo mítico, para um épico, para um conto [...]' (TURNER, 1982, p. 22, ênfase do autor). (CAVALCANTI, 2013, Online)
}

O embate nessas disputas, para além da arena esportiva, invoca valores das masculinidades através de formas de expressão que hierarquizam corpos. É uma disputa corporal, verbal e valorativa. Desta maneira, o canto na partida não se refere apenas ao jogo. Ele é um texto propagandístico que diz das formas de controle do ambiente social. Entendemos aqueles cânticos 
como fragmentos de uma textualidade maior e, desta maneira, como uma ação deliberada, parte da maquinaria do discurso de ódio, como dispositivos que ensinam a ver e a falar sobre determinado tema.

Berenice Carpegiani (2017, p. 13) explica que "odiar consiste tanto em evitar o que se odeia quanto em gerar mecanismos para a sua destruição". Se por um lado o ódio aponta para a destruição do grupo odiado, por outro lado ele será o amálgama para o grupo que odeia (CARPEGIANI, 2017). Guardado em suas crenças, o grupo que odeia acredita fazer justiça ao distribuir seus valores a partir de práticas discursivas. Tais práticas são estrategicamente orquestradas. A depreciação da pessoa, grupo ou hábitos odiados repercute primeiro simbolicamente e depois alcança materialmente os corpos. Neste sentido, voltemos os olhos à trajetória de Bolsonaro e à rede de sentidos por ele produzida a partir de seus discursos. Como deputado, ele criou uma trama discursiva sustentada em falas violentas contra mulheres, pessoas homossexuais e população negra. Bolsonaro tomou os programas populares de televisão como um palco privilegiado para a expressão de suas ideias ultraconservadoras. Em país com um rico histórico de violência contra a população LGBT, uma de suas máximas foi "Ter filho gay é falta de porrada!". Diante desta fala, o Portal Geledés Instituto da Mulher Negra ${ }^{9}$ relembrou um dado importante: "De acordo com a Secretaria Nacional de Direitos Humanos, a grande maioria das denúncias de homofobia recebidas pelo Disque 100 (em 2011 foram quase 7 mil) são de violências sofrida por gays dentro de casa, 42\%". Reeleito, em 2014, como deputado federal mais votado pelo RJ e terceiro mais votado no Brasil, as falas de Bolsonaro foram manchete no Portal Exame ${ }^{10}$. A matéria lembrava a violência contra a deputada Maria do Rosário (PT/RS), quando o político disse que, por ser muito feia e não fazer seu tipo, a deputada não merecia ser estuprada; as ofensas dirigidas à ex-presidenta Dilma Rousseff e à ministra Eleonora Miniccuci, chamando-as de "sapatona"; e para a cantora Preta Gil. No último caso, a fala ocorreu ao responder uma pergunta enviada pela cantora ao programa televisivo CQC (Band TV). Preta Gil quis saber qual reação teria Bolsonaro caso um de seus filhos se apaixonasse por uma mulher negra. Respondeu o então deputado: "Preta, eu não vou discutir promiscuidade com quem quer que seja. Eu não corro esse risco. Meus filhos foram muito bem educados e não viveram em ambiente como lamentavelmente é o teu". 
Sabemos que nenhum texto guarda em si o sentido e que este surge em ocasiões de interlocução, em determinada situação comunicacional. Para além da relação sociocomunicativa, a fim de serem compreendidos, eles exigem dos interlocutores o reconhecimento de suas dimensões pragmáticas, semântico-conceitual e formal. São muitos os fatores de textualidade (LEAL, 2018). Entretanto, ressaltaremos, diante de nossas perguntas, três fatores: intencionalidade, situacionalidade e intertextualidade. O primeiro está focado nos objetivos do texto em uma situação de comunicação, da intenção do enunciador diante do alocutário. Este fator nos esclarece que não há textos neutros, sempre haverá uma intencionalidade por parte de quem produz um texto. A situcionalidade é a adequação do texto ao contexto, bem como a orientação do sentido do discurso. A produção e a interpretação dos textos estão atravessadas por valores dos sujeitos envolvidos no evento comunicativo. Neste sentido, a situcionalidade deve ser considerada do texto para a situação de comunicação e desta para o texto, uma vez há sempre uma mútua interferência. Desta maneira, os sujeitos da comunicação devem considerar a adequação texto/situação. O terceiro fator aqui sublinhado envolve as relações extra-textuais, as interligações dos textos entre si, o conhecimento que permite perceber a textos e contextos. Textos são intertextuais (LEAL, 2018).

Se considerarmos nossas inquietações à luz do pensamento de Paul Ricoeur, levando em conta o conjunto da obra do autor, podemos dizer que estávamos nos acercando do debate por ele proposto sobre o texto e a ação. Geraldo De Mori (2012, p. 42) relembra que Ricoeur sustenta em quatro pilares sua teoria dos textos: "1) a efetuação da linguagem como discurso; 2) a explicitação do discurso como obra; 3) a projeção pela obra de um mundo, o 'mundo do texto'; 4) a mediação deste mundo na compreensão do si..". Seguindo as observações de De Mori (2012), a linguagem consuma-se, primeiramente, como discurso que, enquanto evento, se refere a um mundo e se dirige a um interlocutor. Entretanto, sublinha o pesquisador, na qualidade de sentido, o discurso "ultrapassa a si mesmo como evento, por causa da perspectiva significante da linguagem. A significação nada mais é do que a exteriorização do dizer no dito." (DE MORI, 2012, p. 43). Sob essa lógica, o pesquisador observa que o texto forma-se a partir da palavra escolhida pelo locutor para dizer algo para alguém. 


\section{Gênero, homofobia e dispositivos discursivos das masculinidades}

Não há gênero fora da linguagem, como também não há texto sem intertextualidade. Desta maneira, as tramas textuais nos atos comunicacionais atualizam o gênero e suas normatizações. Indo ao encontro das proposições de Judith Butler (2012), o gênero pode ser compreendido como performativo, ou seja, como um fazer continuado e como uma atividade. Inspirando-se na teoria dos atos de fala de Austin, Butler (2012) dirá que é por uma repetição que se dá tanto no discurso quanto no corpo que, ao longo do tempo, o gênero adquire uma aparência de naturalidade, ou seja, que passa a ser visto como a-histórico e invariável. Sob tal lógica, à qual nos filiamos, a própria nomeação de um sexo consistiria em um ato de dominação e de coerção que orienta/restringe possibilidades de existência.

Raewyn Connell (2003) importante referência para os estudos das masculinidades, sinaliza que a maior parte daquilo que ela chama de ordens de gênero (em referência às maneiras de corporificação social dessas normas) seria patriarcal, ou seja, construiria privilégios aos homens (e a determinados homens, mais especificamente), ao passo que subordinaria mulheres (e também outros grupos de homens).

Para além de definir as masculinidades como um objeto, faz-se necessário compreendê-las com base nos processos e nas relações por meio das quais os sujeitos vivem suas vidas ligadas aos gêneros. A masculinidade, portanto, poderia ser descrita como "um lugar nas relações de gênero, como as práticas através das quais homens e mulheres ocupam esse espaço no gênero e os efeitos dessa prática na experiência corporal, na personalidade e na cultura" (CONNELL, 2003, p. 109, tradução nossa) ${ }^{11}$. Mais do que algo isolado, é igualmente relevante observar a existência não de uma masculinidade, no singular, mas de múltiplas masculinidades, no plural, as quais são constituídas e atravessadas por questões como etnia, classe social e orientação sexual (CONNELL, 2003).

Michael Kimmel (1998) argumenta que as masculinidades são fruto de uma construção social e cultural, que são plurais e variáveis e que, inclusive no curso de vida de um mesmo indivíduo, podem exigir dele diferentes

11 "un lugar en las relaciones de género, en las prácticas a través de las cuales los hombres y las mujeres ocupan ese espacio en el género, y en los efectos de dichas prácticas en la experiencia corporal, la personalidad y la cultura (CONNELL, 2003, p. 109). 
posicionamentos. As masculinidades, pois, constituir-se-iam com base em dois fatores que seriam asseverados por disputas de poder: o primeiro seria em relação às mulheres e o segundo em relação aos outros homens (os negros, os velhos, os pobres, os homossexuais). Em ambos os casos, contudo, haveria uma relação hierárquica fortemente marcada. "Assim, dois dos elementos constitutivos na construção social de masculinidades são o sexismo e a homofobia" (KIMMEL, 1998, p. 105). Compreendendo, outrossim, como fundamental perceber os gêneros a partir das relações de poder que os atravessam/constituem, Miguel Vale de Almeida (1995, p. 17) sugere que a masculinidade seja tomada como "um processo construído, frágil, vigiado, como forma de ascendência social que pretende ser".

Desde o título do presente artigo falamos em dispositivos discursivos das masculinidades (KOLINSKI MACHADO, 2018). Rosa Maria Bueno Fischer (2002), ao discutir o que denomina como sendo o dispositivo pedagógico da mídia, a partir de uma matriz foucaultiana, salienta como a televisão, mais especificamente, sendo partícipe do processo de constituição de subjetividades, age no sentido de ensinar aos seus públicos os modos de ser e de se estar na cultura.

A esta altura, recuperamos o fator intencionalidade e situcionalidade na produção das textualidades ao propormos que se percebam os cânticos homofóbicos das torcidas de futebol como dispositivos discursivos das masculinidades. Sugerimos que tais falas, pedagógicas, sejam compreendidas como aparatos que, inseridos em determinada ordem discursiva, dão a ver quais são as possibilidades (e as impossibilidades) de se ser e de se estar no mundo como homem, delimitando, assim, espaços permitidos e interditados aos corpos masculinos e, ainda, salientando inclusive as sanções físicas passíveis àqueles que romperem com essa lógica heteronormativa (WARNER, 1991). A identidade, como sugerem trabalhos de Stuart Hall (2000) e Judith Butler (2003), funda-se, em grande medida, a partir da diferença. Para saber aquilo que se é - ou, nesse caso, aquilo que se deve ser - é fundamental que se ressalte aquilo que não se é - ou aquilo que não se deve ser.

"Maria, eu sei que você treme sempre que o galo vai jogar"12 é um refrão continuamente entoado por torcedores (e por torcedoras) do Clube Atlético Mineiro em jogos contra o Cruzeiro Esporte Clube. Para além da enraizada rivalidade, já mencionada, o cântico, machista e homofóbico, reúne tudo 
aquilo que se afasta de uma masculinidade hegemônica (o feminino e, por conseguinte, a mulher e o homossexual) a fim de desqualificar a torcida adversária. O mesmo se dá na via oposta. Em relação à torcida do Cruzeiro Esporte Clube são comuns cânticos que, ao interpelarem os torcedores do Clube Atlético Mineiro, o façam por "frangas". O galo, para ser espezinhado, precisa ser convertido em seu par feminino (ou afeminado). “Frangas, me diz como se sente em ser segundo nas Gerais. Mesmo que se passem os anos não vou me esquecer jamais"'ı3. O mesmo cântico, vale salientar, mais adiante faz alusão ao fato de o Atlético ter lançado, em 2010, uma versão de sua camisa de treino na cor rosa (cor essa, culturalmente, atribuída ao feminino). Na voz dos torcedores, a cor rosa, uma mancha na história do time, configura-se em outro lugar de desqualificação: "Você jogou a série B. De 6×1 te vi perder. Camisa rosa nunca vai sair d'ocê".

Em Gavião virou beija-flor ${ }^{14}$ torcedores do São Paulo Futebol Clube evocam, a partir de uma lógica homofóbica - e também transfóbica - uma série de acontecimentos envolvendo ex-jogadores do Sport Clube Corinthians Paulista. "Gambá, me diz como se sente. Por que você gosta de beijar? Ronaldo saiu com dois travecos. O Sheik selinho ele foi dar. Vampeta posou pra G. Dinei desmunhecou. Na Fazenda de calcinha ele dançou. Não adianta argumentar. Todo mundo já falou. Que o gavião virou um beija-flor". Os eventos então citados (encontros com travestis, ensaio fotográfico para revista voltada ao público gay, performance em um reality show), ao abordarem de modo pejorativo práticas que, sob determinada perspectiva, afastariam os envolvidos de uma masculinidade hegemônica/heterossexual, servem, mais uma vez, para desqualificar os adversários. A resposta do Corinthians segue a mesma lógica. "Vai pra cima delas, Timão! Da bicharada"m5.

Tal qual ensina Didier Eribon (2008, p. 111), a homossexualidade é contínua e historicamente referida como algo que escapa à normalidade, constituindose na sexualidade e/ou afetividade em que falta algo: "é uma "perversão", uma "parada" num estágio infantil no desenvolvimento normal do indivíduo e de seus desejos, uma "incapacidade de reconhecer o outro". A partir de um discurso heterocentrado, baseado em uma mitologia científica, a identidade homossexual é, desde a sua gênese, negativa. 
Perceber, assim, que nossa cultura estrutura-se ao redor de um paradigma heteronormativo é mais do que dizer que ela é apenas heterossexual, é dar a ver que o privilégio heterossexual reside no fato de que a cultura heterossexual se apresenta, de forma totalizante, como sociedade (WARNER, 1991). A heteronormatividade, ao definir a heterossexualidade como natural e ao seccionar os sujeitos entre heterossexuais e não heterossexuais, diz quem é normal e quem não é. A fronteira que se estabelece aí, pois, separa as vidas que pesam daquelas que geram apenas o asco (BUTLER, 1993).

A homofobia, nesse contexto, é a consequência lógica de todo um processo que incita o ódio à determinada diferença. De acordo com Daniel Borrillo (2010, p. 13), seria uma manifestação arbitrária que "consiste em designar o outro como contrário, inferior ou anormal".

Ao recorrer à homofobia como exercício desclassificatório, os cantos das torcidas delegam a homossexualidade ao espaço do ilícito. Neste sentido, a homofobia é participante ativa no que se refere à configuração da heterossexualidade como padrão natural de conduta, bem como de dicotomias e de binarismos que marcam as configurações de gênero. Conforme lembra Byrne Fone (2000), a homofobia representa o risco de desestabilização que a homossexualidade pode gerar, perturbando convenções sociais, políticas e econômicas, bem como as performances de gênero esperadas de homens e de mulheres.

"À semelhança de qualquer forma de exclusão, a homofobia não se limita a constatar uma diferença: ela a interpreta e tira suas conclusões materiais" (BORRILLO, 2010, p. 16). Nesse sentido, seja pela violência da injúria, seja pelos ataques físicos contra homossexuais, ao ser responsável por sua "falha", uma condenação moral e coletiva faz-se necessária.

Torcedores e torcedoras do Coritiba Foot Ball Club, em partidas nas quais o seu time enfrenta o Club Athletico Paranaense, entoam um canto, mais uma vez, homofóbico. Nesse caso, novamente, há uma desqualificação do adversário a partir da menção a práticas sexuais não heterossexuais. "Atleticano porco. Filho da puta. Rebola, que eu vou comer sua bunda. Nasceu no chiqueiro, não tem onde dormir. E quando acha graça, não tem dente para rir. Pau no cu do Atlético. Cuzão ${ }^{16 " .}$ Como represália, a torcida do Athletico Paranaense fala em "chupar rola" e "dar o cu"17.

16 Disponivel em: <https://www.youtube.com/watch?v=Vqh1yzaHdgM>. Acesso em: Dez 2019.

17 Disponível em: <https://www.youtube.com/watch?v=KSGY4wCCTmc>. Acesso em: Dez 2019. 


\section{À guisa de uma conclusão: o estádio como lugar de exercício pedagógico e a homofobia como prática discursiva estruturante}

No ano de 2007, houve a reedição ampliada da obra “O estigma do passivo sexual: um símbolo de estigma no discurso cotidiano", de Michel Misse. Nesta edição, Peter Fry (2007, p. 12), responsável pela apresentação da obra, comentou:

Outro dia fui assistir um jogo de futebol no Maracanã. Antes do jogo, uma das torcidas de jovens homens marchava em volta do estádio como um pelotão de exército, emitindo quantas vezes fosse necessário em vozes grossas e másculas as palavras “Ó! Fúria, chupa rola, dá o cu' para tentar reduzir a torcida oposta à condição de um vencido, de 'passivo sexual'.

À maneira de um rito comunicacional, após 13 anos, ouvimos o mesmo canto no entorno e no interior dos estádios como parte de uma estratégia de diminuição do opositor. Gustavo Bandeira (2010, p. 342) propõe que os estádios de futebol sejam compreendidos como um local que "institucionaliza práticas, ensina, produz e representa masculinidades". Avançando nessa direção, o pesquisador ainda afirmará que "os estádios de futebol [...] exercem pedagogia. Podendo pensar em uma cultura de estádios de futebol, é necessário um processo de aprendizagem para que os sujeitos possam ser introduzidos nessa cultura" (BANDEIRA, 2010, p. 344). Os cânticos então entoados, para Bandeira (2010), consistiriam em ritos orais os quais dariam a ver sentimentos e ideias coletivas de determinado grupo, reunindo tal grupo a partir de uma forma de enunciação que produz distinções (nós e eles) e, consequentemente, hierarquias.

Os cânticos repetidos, as performances executadas e as emoções explicitadas são didaticamente empregados, produzindo uma lógica de atitudes fundamental para o tipo específico de fruição dos espetáculos futebolísticos nos estádios. Dentre os mais variados conteúdos que se ensinam, aprendem e disputam nos estádios de futebol a masculinidade possui preponderância. É importante frisar que a masculinidade vivida nesse contexto cultural específico possui algumas características particulares: ela é machista e homofóbica (BANDEIRA e SEFFNER, 2013, p. 247).

Os cânticos entoam mais do que a injúria. Eles se fazem ameaça. Ao debruçar-se sobre o estudo e o detalhamento do conceito de violência, Heleieth 
Saffioti (2015, p. 18) observou que "o entendimento popular da violência apoia-se num conceito, durante muito tempo, e ainda hoje, aceito como o verdadeiro e o único. Trata-se da violência como ruptura de qualquer forma de integridade da vítima: integridade física, integridade psíquica, integridade sexual, integridade moral." Os cantos homofóbicos das torcidas entoam palavras que dão a ver textos de desclassificação, de exclusão e de ódio - portanto, rupturas da integridade sexual e moral. Os cânticos homofóbicos das torcidas não são algo intrínseco ao "futebol raiz". Eles são parte das práticas sociais de ordenamento de gênero (CONNELL \& PEARSE, 2015), consistindo em um crime que se faz em rede. A situação vivida por Luiz Othavio Nunes, no metrô de São Paulo, mencionada na introdução deste artigo, deixa ver que o discurso não se limita aos sentidos fechados dos signos, que aqueles enunciados ameaçadores não estavam contidos dentro das fronteiras do "mundo do futebol". Fora dos campos e na outra ponta da curvatura, mas sob o mesmo arqueamento de violência, no dia 16 de outubro de 2018, uma travesti foi esfaqueada por cinco homens, no centro de São Paulo ${ }^{18}$. Segundo testemunhas, os assassinos, enquanto praticavam o ato, gritavam "ele sim", aludindo apoio ao então candidato Bolsonaro. A revista Carta Capita ${ }^{19}$ publicou um mapeamento, realizado pelo pesquisador e jornalista Haroldo Ceravolo, que revelava o aumento de casos de violência motivados pela disputa presidencial. Durante aquele período eleitoral houve um crescimento no número de registros de violência praticada por apoiadores do então candidato Bolsonaro. A revista informava, à época, a criação da plataforma \#VítimasDalntolerância para registrar e denunciar situações de violência que tiveram como ponto de partida motivações eleitorais. O discurso, contudo, ultrapassa tais motivações e os muros dos estádios. Neste sentido, devemos nos lembrar que a significação estará sempre ligada às formas de exteriorização do discurso. Queremos dizer, a significação potencializa manifestações múltiplas do discurso, permitindo-o comunicar-se para distintos interlocutores. Assim, não existe o "isso não ofende ninguém" ou o "não estamos falando especificamente com o torcedor", tal qual afirmou o presidente da torcida organizada Galoucura. Se entendermos a significação como formas de representações mentais de determinado signo, compreenderemos bem o impacto que terá esta exteriorização do discurso homofóbico contido nos cânticos de futebol. 
Carlos Magno Camargos Mendonça é professor no PPG em Comunicação da UFMG. É doutor em Comunicação e Semiótica pela Pontifícia Universidade Católica de São Paulo - PUCSP e realizou pós-doutorado na Universidad Complutense de Madrid. Desenvolve pesquisas com foco na relação entre comunicação e estudos de gênero, performance, corpo, homossexualidade masculina e propaganda, com financiamentos do CNPq e da Fapemig. É um dos líderes de pesquisa do Núcleo de Estudos em Estéticas do Performático e Experiência Comunicacional - NEEPEC e membro da equipe de pesquisadores do projeto de cooperação internacional UFMG/Universidad Complutense de Madrid (Espanha). É autor do livro "E o verbo se fez homem. Corpo e Mídia".

macomendonca@gmail.com

Felipe Viero Kolinski Machado Mendonça é professor do PPG em Comunicação da Universidade Federal de Ouro Preto. É Doutor em Ciências da Comunicação pela Unisinos. Realizou estágio doutoral no Centro em Rede de Investigação em Antropologia, em Lisboa. Tem pós-doutorado pela UFMG. Integra os grupos de Pesquisa Núcleo de Estudos Tramas Comunicacionais: Narrativa e Experiência (UFMG) e o Ponto: afetos, gêneros, narrativas (UFOP). Tem experiência profissional/estágio em rádio e em televisão. Em suas pesquisas, aborda produção de sentidos nas mídias e no jornalismo; análise do discurso midiático e estudo de rotinas produtivas; gêneros e sexualidades; teoria queer e cultura pop.

felipeviero@gmail.com

Contribuição de cada co-autor: ambos trabalhamos na 1) fundamentação teórica e conceituação; 2) investigação de campo; 3) metodologia e 4) análise formal do corpus. Carlos Magno Camargos Mendonça: Escrita - Primeira Redação. Felipe Viero Kolinski Machado Mendonça: Escrita - Revisão e Edição.

\section{Referências}

ALMEIDA, M. B.; DA SILVA SOARES, A. O futebol no banco dos réus: caso da homofobia. Movimento, v. 18, n. 1, 2012.

BANDEIRA, G. A.; SEFFNER, F. Futebol, gênero, masculinidade e homofobia: um jogo dentro 
do jogo. Espaço Plural, v. 14, n. 29, 2013.

Um currículo de masculinidades nos estádios de futebol. Revista Brasileira de Educação, v. 15, n. 44, 2010.

BORRILLO, D. Homofobia: história e crítica de um preconceito. Belo Horizonte: Autêntica, 2010.

BUTLER, J. Bodies that matter: on the discourse limits of sex. Nova lorque e Londres: Routledge, 1993.

Problemas de gênero: feminismo e subversão da identidade. São Paulo: Editora Record, 2012.

CARPIGIANI, B. Sob o prisma do ódio. In: ARAÚJO, P. R. M,; CARPIGIANI, B.; PEREZ, C.; DANTAS, B. S. A.; CARVALHO, F.O. Ensaios sobre o ódio. São Paulo: Editora LiberArs, 2017.

CAVALCANTI, M. L. V. C. Drama, ritual e performance em Victor Turner. In: Sociologia e Antropologia, Rio de Janeiro, v.3, n. 6, Jul./Dec., 2013.

CONNELL, R. W. Masculinidades. México: Universidad Nacional Autónoma de México, 2003.

; PEARSE, R. Gênero: uma perspectiva global. São Paulo: Versos, 2015.

DE MORI, G. A teoria do texto e da narração de Paul Ricoeur e sua fecundidade para a teologia. In: Teoliterária, Belo Horizonte, v.2. n.3, 2012.

ELLUL, J. Propagandas: uma análise estrutural. Lisboa: Antígona, 2014.

ERIBON, D. Reflexões sobre a questão gay. Rio de Janeiro: Companhia de Freud, 2008.

FISCHER, R. M. B. O dispositivo pedagógico da mídia: modos de se educar na (e pela) TV. In: Educação e Pesquisa, São Paulo, v.28, n.1, jan./jun. 2002.

FONE, B. Homophobia: A history. Nova lorque: Macmillan, 2000.

FRY, P. Apresentação. In: MISSE, M. O estigma do passivo sexual: um símbolo de estigma no discurso cotidiano. Rio de Janeiro: Booklink, 2007.

HALL, S. Quem precisa da identidade? In: SILVA, T. T. Identidade e diferença: a perspectiva dos estudos culturais. Petrópolis, RJ: Vozes, 2000.

KIMMEL, M. S. A produção simultânea de masculinidades hegemônicas e subalternas. Horizontes antropológicos, v. 4, n. 9, 1998.

KOLINSKI MACHADO, F.V. Homens que se veem: masculinidades nas revistas Junior e Men's Health Portugal. Ouro Preto: Editora UFOP, 2018.

LASSWELL, H. Propaganda technique in the world war. Eastford: Martino Fine Books, 2013.

LEAL, B. Do texto à textualidade na comunicação: contornos de uma linha de investigação. Textualidades Midiáticas. Belo Horizonte: PPGCOM UFMG, 2018. 
SAFFIOTI, H. Gênero, Patriarcado e Violência. São Paulo: Expressão Popular, 2015.

SPINOZA, B. Ética. Belo Horizonte. Autêntica Editora. 2007.

STEWART, K. A space on the side of the road. Princeton: Princeton University Press. 1996 Ordinary affects. Durham: Duke University Press Book. 2007

TURNER, V. Drama, campos e metáforas. Niterói: EdUFF, 2008.

From ritual to theatre: the human seriousness of play. Nova lorque: PAJ Publications, 1882.

Symbolic studies. Annual Review of Anthropology, 4, 1975.

VOLLI, U. Semiótica da publicidade. Lisboa: Edições 70, 2003.

WARNER, M. Fear of a Queer Planet: Queer Politics and Social Theory. Londres, University of Minnesota Press, 1991.

Artigo recebido em 06/01/2020 e aprovado em 24/07/2020. 